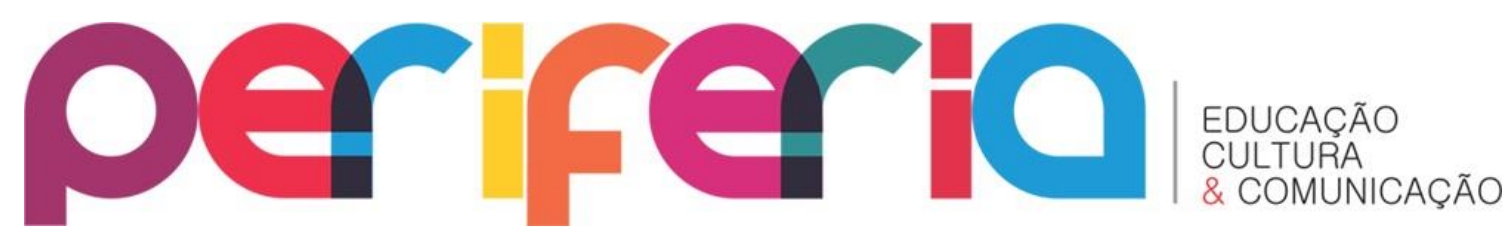

ISSN:1984-9540

DOI: $10.12957 /$ periferia.2019.36363

\title{
CAMINHOS POSSÍVEIS PARA PRODUÇÃO DE PRÁTICAS PEDAGÓGICAS NO ENFRENTAMENTO DAS VIOLÊNCIAS DE GÊNERO E SEXUALIDADE
}

\author{
Daniel Vieira Silva ${ }^{1}$ \\ Universidade do Estado do Rio de Janeiro
}

\section{Resumo}

0 presente trabalho apresenta achados de pesquisa de mestrado realizada entre os anos de 2015 e 2017, no âmbito do Programa de Pós Graduação em Educação, Cultura e Comunicação (PPGECC/UERJ), onde foram investigadas as possibilidades, desafios e potências na produção de práticas pedagógicas voltadas para a discussão das temáticas relacionadas à gênero e sexualidade no espaço escolar. A partir dos relatos e experiências de quatro professoras da rede municipal de Nova lguaçu, município da região metropolitana do estado do Rio de Janeiro, foi possível perceber elementos que diferenciam as práticas produzidas por essas professoras a partir do olhar atento para as questões de violência, marginalização e produção de desigualdade frente às percepções e performances de gênero e sexualidade. Inicialmente, serão apresentadas algumas reflexões sobre as relações de gênero e sexualidade na escola, e em seguida nos aproximaremos das possibilidades na produção de práticas pedagógicas que se coloquem como ferramentas de questionamento e enfrentamento da violência e marginalização.

Palavras-chave: práticas pedagógicas, gênero, sexualidade.

\footnotetext{
${ }^{1}$ Doutorando do Programa de Pós Graduação em Educação (PROPED/UERJ), Mestre pelo Programa de Pós Graduação em Educação, Cultura e Comunicação (PPGECC/UERJ). E-mail: daniel.febf@gmail.com
} 


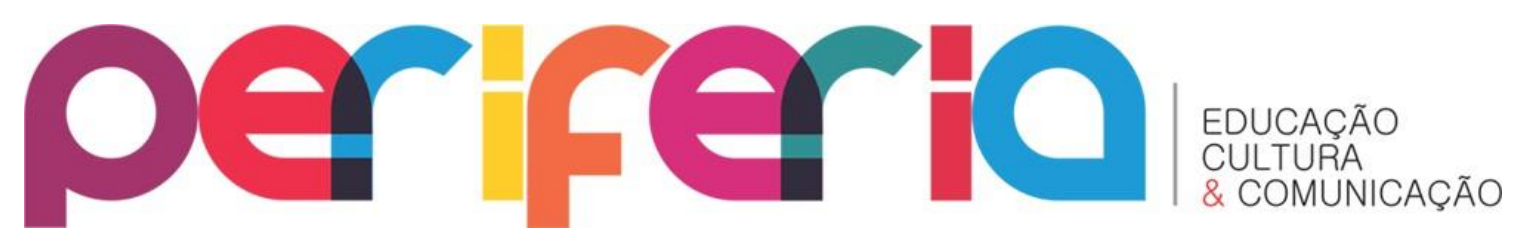

ISSN:1984-9540

DOI: $10.12957 /$ periferia.2019.36363

\title{
POSSIBLE PATHWAYS FOR THE PRODUCTION OF PEDAGOGICAL PRACTICES IN THE COUNSELING OF GENDER AND SEXUALITY VIOLENCES
}

\begin{abstract}
The present work presents findings of a master 's research carried out between the years of 2015 and 2017, by the Graduate Program in Education, Culture and Communication (PPGECC / UERJ), where the possibilities, challenges and potentials in the production of pedagogical practices were investigated to the discussion of the themes related to gender and sexuality in the school space. From the reports and experiences of four teachers from the municipal network of Nova Iguaçu, municipality of the metropolitan region of the state of Rio de Janeiro, it was possible to perceive elements that differentiate the practices produced by these teachers from the attentive look at issues of violence, marginalization and the production of inequality against the perceptions and performances of gender and sexuality. Initially, some reflections on gender relations and sexuality in school will be presented, and then we will approach the possibilities in the production of pedagogical practices that are placed as tools of questioning and facing violence and marginalization.
\end{abstract}

Keywords: pedagogical practices, gender, sexuality. 


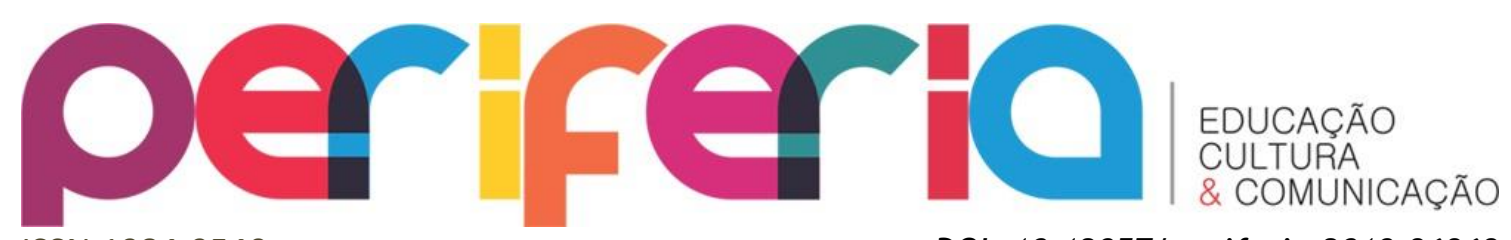

ISSN:1984-9540

DOI: $10.12957 /$ periferia.2019.36363

\section{CAMINOS POSIBLES PARA LA PRODUCCIÓN DE PRÁCTICAS PEDAGÓGICAS EN EL ENFRENTAMIENTO DE LAS VIOLENCIAS DE GÉNERO Y SEXUALIDAD}

\section{Resumen}

El presente trabajo presenta resultados de investigación realizada entre los años 2015 y 2017, por el Programa de Post Graduación en Educación, Cultura y Comunicación (PPGECC / UERJ), donde se investigaron las posibilidades, desafíos y potencias en la producción de prácticas pedagógicas orientadas hacia la discusión de las temáticas relacionadas con el género y la sexualidad en el espacio escolar. A partir de los relatos y experiencias de cuatro profesoras de la red municipal de Nova Iguaçu, municipio de la región metropolitana del estado de Río de Janeiro, fue posible percibir elementos que diferencian las prácticas producidas por esas profesoras a partir de la mirada atenta a las cuestiones de violencia, marginalización y producción de desigualdad frente a las percepciones y performances de género y sexualidad. Inicialmente, se presentarán algunas reflexiones sobre las relaciones de género y sexualidad en la escuela, y luego nos acercaremos a las posibilidades en la producción de prácticas pedagógicas que se coloquen como herramientas de cuestionamiento y enfrentamiento de la violencia y marginación.

Palabras clave: prácticas pedagógicas, género, sexualidad 


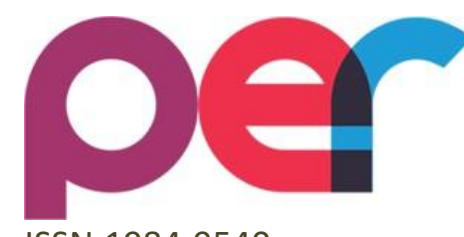

ISSN:1984-9540

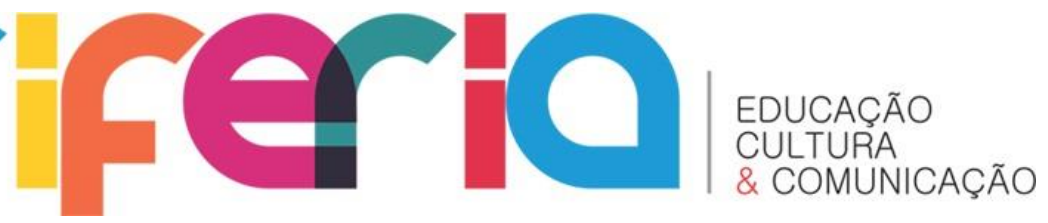

DOI: $10.12957 /$ periferia.2019.36363

Introdução

0 presente artigo apresenta achados de pesquisa desenvolvida no âmbito do programa de pós graduação em Educação, Cultura e Comunicação (PPGECC/UERJ) onde foram investigadas as possibilidades, desafios e potências na produção de práticas pedagógicas voltadas para a discussão das temáticas relacionadas à gênero e sexualidade no espaço escolar.

A partir dos relatos e experiências de quatro professoras da rede municipal de Nova Iguaçu, município da região metropolitana do estado do Rio de Janeiro, foi possível perceber elementos que diferenciam as práticas produzidas por essas professoras a partir do olhar atento para as questões de violência, marginalização e produção de desigualdade frente às percepções e performances de gênero e sexualidade. A pesquisa foi desenvolvida com base em conversas individuais e em grupo, buscando levantar e problematizar em conjunto as memórias, percepções e fazeres das professoras participantes. Cabe ressaltar que o principal critério para a escolha dessas profissionais foi o fato de terem cursado o curso de extensão Gênero e Diversidade na Escola, no ano de 2014 pela UFRJ.

As temáticas de gênero e sexualidade na escola estão envoltas em vários entrelaçamentos. $\mathrm{Na}$ escola, se há não muito tempo o debate sobre sexualidade era restrito a questões biológicas e de saúde, hoje percebemos a necessidade de se incluir questões voltadas para a diversidade. Assim, a discussão sobre a construção sócio histórica das relações de gênero e sexualidade passam a habitar o espaço escolar, tornando-se disparadoras de dúvidas, conflitos e possibilidades de trabalho docente. Não se trata de dizer que somente agora a escola está permeada pela diversidade, e sim de que esse fator passa a ser objeto de análise do campo de estudo educacional.

Dessa forma, para além de reconhecer a diversidade em seus atores, a escola deveria refletir sobre as relações que instituem desigualdades. No entanto, falar de "diversidade" não faz com que a escola passe necessariamente a se preocupar com as relações de poder que hierarquizam as diferenças. A presença do debate sobre 


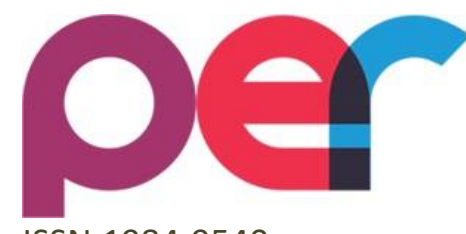

ISSN:1984-9540

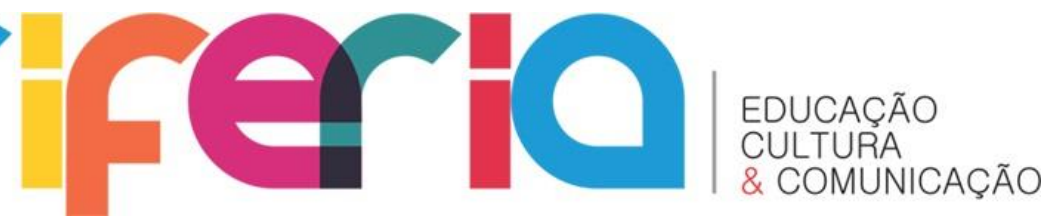

DOI: $10.12957 /$ periferia.2019.36363

diversidade na escola também esbarra em questões instituídas, que podem subverter os propósitos e oferecer sentidos variados para a "diversidade".

Falando sobre as opressões ligadas à identidade de gênero e sexualidade, é importante colocar em questão outros conceitos que dão base para se pensar nas violências que são identificadas como homofóbicas, transfóbicas, lesbofóbicas ou bifóbicas. Por mais que LGBTfobia represente as experiências de violência vivenciadas por sujeitos LGBT's, estas violências se configuram a partir de construções sociais e históricas.

Rich (1980) trouxe uma definição para o conjunto de normas que incide sobre a construção de gênero e a naturalização da heterossexualidade. Por entender que as duas questões estão entrelaçadas, a autora demarca a necessidade de compreendê-las juntamente para que se possa perceber de que maneira nossa sociedade estipula padrões ligados à sexualidade. Assim, a autora utiliza o termo heterossexualidade compulsória para compreender de que maneira gênero e sexualidade estão interligados, oferecendo sentido ao discurso hegemônico, quando este estabelece que, para que os corpos façam sentido, é necessário que haja um acordo entre sexo e gênero, orientados dentro da lógica heterossexual.

Para Colling e Nogueira (2014), "a heterossexualidade compulsória consiste na exigência de que todos os sujeitos sejam heterossexuais, isto é, se apresenta como única forma considerada normal de vivência da sexualidade" (p. 176). Esse conceito traz uma importante contribuição, ao buscar desnaturalizar a heterossexualidade. Os autores ressaltam, por exemplo, que a homossexualidade ainda é alvo de diversas pesquisas científicas que buscam encontrar suas causas. Junqueira (2007) diz que, até 2007, já existiam mais de setenta teorias sobre as causas da homossexualidade. Ao discutirmos heterossexualidade compulsória, passamos a denunciar os modos com que a heterossexualidade é imposta como o único modo natural e saudável de vivência da sexualidade e como as formas não heterossexuais de sexualidade são consideradas desviantes em diversos sentidos, inclusive nos discursos médicos, científicos, biológicos e pedagógicos. 


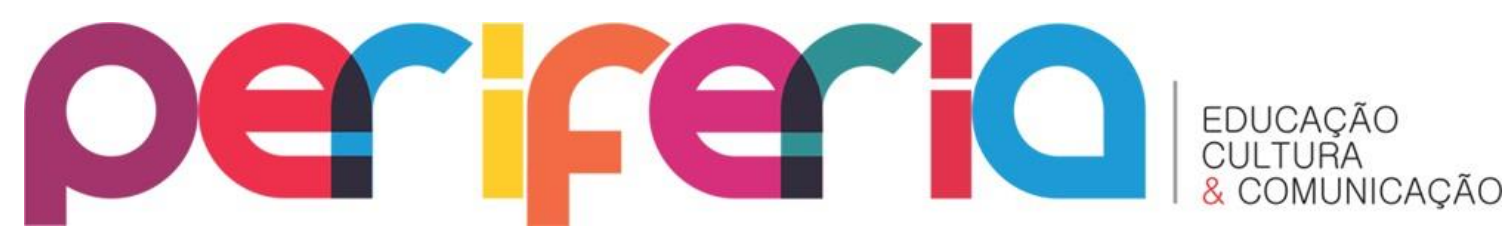

ISSN:1984-9540

DOI: $10.12957 /$ periferia.2019.36363

0 que a escola tem a ver com isso?

A escola não inventou a hierarquia de gênero; sequer inventou o gênero, a sexualidade, a raça ou a classe. Porém, como instituição social, perpetua modelos e reverbera práticas discursivas que instituem desigualdades. Essa reprodução é especialmente perigosa quando compreendemos a escola como instituição responsável por propagar e difundir os conhecimentos científicos acumulados pela humanidade. Dessa forma, mais do que apenas reproduzir a lógica hegemônica de gênero, a escola legitima a desigualdade vivenciada por mulheres e pessoas LGBT's.

Dentro do espaço escolar, os marcadores de diferença também se reconfiguram, construindo novas formas de opressão. A própria divisão de turmas em meninos e meninas já é um exemplo de uma segregação que só faz sentido na escola. Em que outro espaço meninas e meninos são divididos por fileiras específicas? Tal divisão facilita a restrição de atividades direcionadas para cada gênero, que são também baseadas na produção histórica de gênero.

A vigilância da escola está sempre presente, buscando evitar que os corpos se desenvolvam fora do esperado. Todos os corpos são educados, porém em sentidos diferentes. As expectativas construídas para cada gênero estão em consonância com o que se espera de mulheres e homens. Essa vigilância se expressa nas roupas, nas falas, nos comportamentos, enfim, nas relações que ali se estabelecem.

Porém, as crianças aprendem, antes de seu ingresso escolar, o que é ou não permitido para seu gênero. Não podemos responsabilizar unicamente a escola por essa construção binária de gênero. Assim como Louro:

Não pretendo atribuir à escola nem o poder nem a responsabilidade de explicar as identidades sociais, muito menos de determiná-las de forma definitiva. É preciso reconhecer, contudo, que suas proposições, suas imposições e proibições fazem sentido, têm "efeitos de verdade", constituem parte significativa das histórias pessoais (LOURO, 2000, p. 21). 


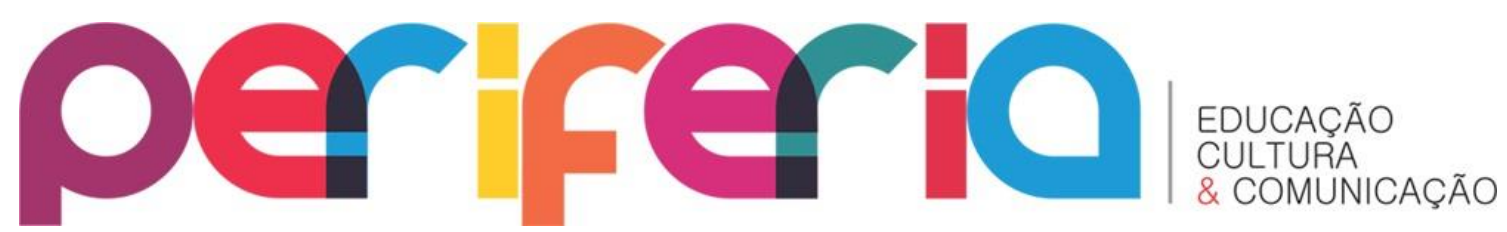

ISSN:1984-9540

DOI: $10.12957 /$ periferia.2019.36363

No entanto, podemos perceber que a escola, geralmente, pouco faz para romper com essa dicotomia, acabando por naturalizá-la. Não apenas reafirma as construções sociais para cada gênero, como produz novas formas de divisão.

\section{"Somos todos diferentes" ou "Viva a diversidade"}

Frases como essas são comuns nas escolas, e na sociedade de forma geral. Exaltar a diferença como uma característica de todo e qualquer sujeito se tornou corriqueiro, e a esperança é que estas afirmações apaguem todas as relações de desigualdade. Porém, é preciso aprofundar a reflexão sobre o que compreendemos como diferença, e os contextos em que estas se tornam marcadores que geram desigualdades e inscrevem os sujeitos em relações de subordinação ou privilégio. Afinal, para o sujeito homossexual, por exemplo, a afirmação de que "ser diferente é legal" não apaga as violências sofridas cotidianamente.

Além disso, os termos diferença e diversidade são utilizados, em geral, para designar as pessoas que são consideradas diferentes com relação a norma, de tal forma que o comportamento "normal" não está incluído nessa diversidade. Nardi e Quartiero (2012), ao falar sobre o uso do termo "diversidade sexual", afirmam:

É importante ressaltar, entretanto, que em seu uso cotidiano acaba por ser tomada como um denominador comum para aqueles e aquelas que não são heterossexuais, ou cuja identidade de gênero não obedece à imposição da linearidade sexo-gênero-sexualidade. É a heteronormatividade que faz com que a heterossexualidade fique excluída do uso corrente do termo diversidade sexual, pois aquilo que é normal não precisa/deve ser nominado, uma vez que é compulsório, ou seja, todos e todas são, até prova em contrário, tidos/as como heterossexuais. (NARDI \& QUARTIERO, 2012, p. 62)

O uso acrítico desses termos tende a esvaziá-los dos sentidos que se propõem. Pensar a diversidade sexual é pensar a diversidade humana, e é preciso nomear nessa diversidade as identidades que são tidas como naturais, normais, legítimas. Numa perspectiva da diversidade, não existe identidade legítima e ilegítima, todas são possíveis e o trabalho desenvolvido deve ser para que existam em situação de 


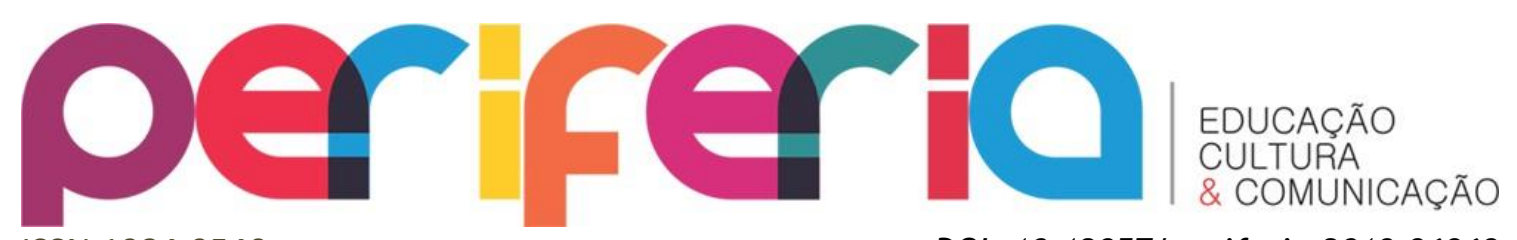

ISSN:1984-9540

DOI: $10.12957 /$ periferia.2019.36363

igualdade. Quando os discursos sobre diversidade focam apenas nos sujeitos que apresentam características que fogem ao considerado normal, corre-se o risco de exotizar a figura do que se considera diferente, e de tratar a temática a partir da lógica da tolerância, que não questiona justamente as relações que elegem determinado sujeito como normal e outro como anormal.

O que o cenário atual nos mostra é que existe o desejo de superar esse paradigma, tornando a escola um espaço de valorização da diferença. É preciso pensar se estamos discutindo realmente as relações de poder que configuram as diferenças em posições de subordinação/privilégio. Para esse objetivo, precisaremos considerar os marcadores de diferença, tais como raça, gênero, sexualidade e classe, como produções históricas e sociais interrelacionadas que perpassam todos os sujeitos.

Tais conceitos, ao serem tensionados por estudos e vivências, passam a ocupar outros espaços, como a produção de políticas públicas. Essas políticas poderão garantir direitos ou aprofundar a desigualdade, e por isso é importante perceber quais são as compreensões sobre gênero e sexualidade que permeiam as políticas públicas, especialmente em um tempo histórico que favorece o debate sobre a população LGBT, mas também está envolto em relações de conflito. Também é necessário refletir sobre as diversas compreensões sobre gênero e sexualidade que habitam o espaço escolar, através de docentes, estudantes, equipe pedagógica, responsáveis, etc. Não basta que a escola esteja disposta a falar sobre diversidade, é preciso que as pessoas que a constroem estejam dispostas a compreender que diversidade é essa, como ela se apresenta, quais são as relações de desigualdade que produz e, principalmente, reconhecer quem são os sujeitos que estão cobertos sob o manto da diferença. Assim, a escola passará, então, a utilizar a noção de diversidade para fazer emergir as discussões sobre LGBTfobia, misoginia, machismo, sexismo, racismo, e diversas outras formas de opressão, ao invés de enterra-las no discurso vazio e ineficaz da tolerância. 


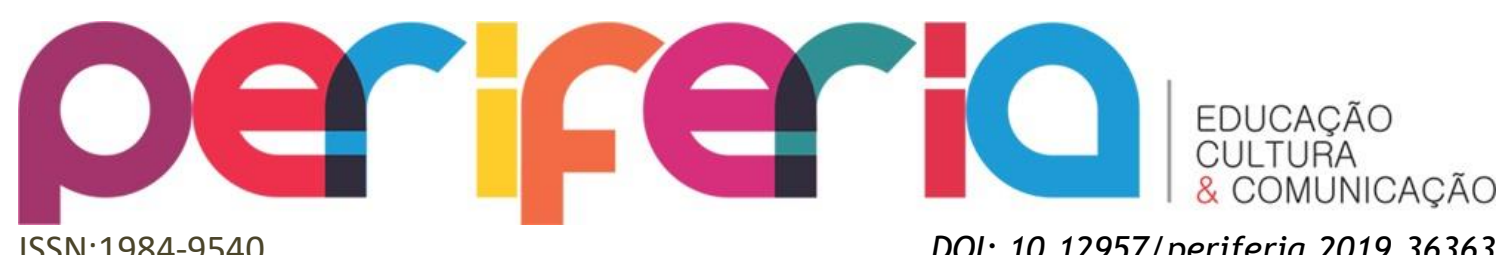

ISSN:1984-9540

DOI: $10.12957 /$ periferia.2019.36363

Desafios e potências na produção de práticas pedagógicas

A pesquisa de mestrado da qual as reflexões e resultados são aqui apresentados dedicou-se a pensar a produção de práticas pedagógicas para o enfrentamento das violências de gênero e sexualidade a partir dos olhares, impressões e experiências de quatro professoras da rede municipal de educação da cidade de Nova Iguaçu, região metropolitana do estado do Rio de Janeiro. $O$ recorte para participação dessas professoras foi o fato de todas serem, além de docentes da mesma rede, ex alunas do curso Gênero e Diversidade na Escola (GDE), em sua edição realizada no ano de 2014 pelo núcleo Diversidade Sexual na Escola, vinculado ao Instituto de Psicologia da Universidade Federal do Rio de Janeiro (UFRJ). Essa política pública se configura como importante estratégia de formação continuada de docentes nas temáticas de gênero, diversidade, sexualidade e raça.

Esse recorte foi fundamental para os objetivos da pesquisa, visto que o objetivo era pensar nas experiências que são desenvolvidas nas escolas, para pensar nos desafios, conflitos, limites, possibilidades, riscos, enfim, todo o conjunto de elementos que configuram as práticas de professoras que assumem um posicionamento político de enfrentamento de violências. Mais do que apenas denunciar as problemáticas existentes nas escolas, gostaríamos de pensar caminhos para superação das violências.

A partir de conversas individuais e coletivas, pudemos ouvir mais dessas professoras quais eram as dificuldades que enfrentavam, suas percepções sobre as diferentes realidades escolares e suas perspectivas sobre as estratégias que podemos desenvolver. Importante destacar que a pesquisa não pretendia avaliar ou mesmo romantizar as práticas apresentadas pelas professoras, mas sim compreender a complexidade do espaço escolar, com verdadeira curiosidade sobre as rotas de fuga, linhas de resistência que elas construíam em seus cotidianos, encarando todas as contradições e limitações como parte do processo em que cada uma se encontra. Afinal, as realidades são múltiplas, e nossas experiências são reflexo do possível. 


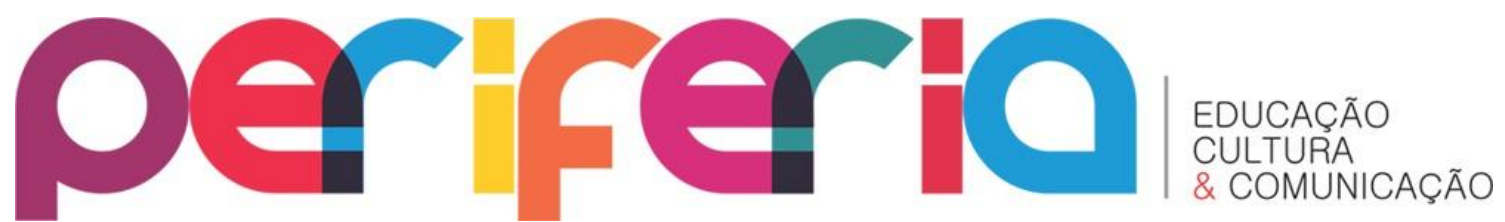

ISSN:1984-9540

DOI: $10.12957 /$ periferia.2019.36363

Destacamos, a fim de compreensão do texto, que todos os nomes são fictícios, e as referências para as falas das professoras trazem a legenda NC, como notas de campo.

Todas as professoras entrevistadas foram unanimes ao dizer que a grande dificuldade que encontram é a resistência e o silêncio dos demais profissionais da escola com relação a discussão de gênero e sexualidade em sala de aula ou em reuniões. Nenhuma das escolas em que elas trabalham já abordaram essas temáticas de forma coletiva. Mais do que o silencio, relataram a resistência de outras/os professoras/es em saber mais do tema. Essa experiência se aproxima do relato de Nardi e Quartiero (2012), ao falar das formações do curso "Educando para a Diversidade":

Um aspecto levantado pelas/os participantes foi a dificuldade de discussão com suas/seus colegas, uma vez que, ao tentarem socializar os assuntos abordados durante a formação, vários colegas da escola não consideraram o tema pertinente ou importante. Os/as colegas, de acordo com os relatos, mostraram-se resistentes em explicitar e discutir a forma com que trabalham com suas/seus alunas/os, mantendo a atitude de "cada um trabalha do seu jeito dentro da sua sala”. (NARDI, QUARTIERO, 2012, p. 81)

Uma palavra presente em todas as entrevistas, e também na conversa coletiva, é "silencio". Para Rita, "a maioria (das/os professoras/es) não se sente preparada para trabalhar esses temas. Não sabe como falar. Tem melindre, né? Medo de ofender. Não sabe como falar então prefere não falar".

Alós (2011) traz algumas questões para refletirmos sobre argumentos do tipo "não sei como trabalhar isso" ou "ignoro como trabalhar essa questão". Ele pergunta:

Quando um professor profere algum desses enunciados, será que ele simplesmente desconhece as questões de educação sexual? Será que ele é apenas incompetente para trabalhar com educação sexual (não no sentido pejorativo, mas apenas sem a devida competência)? Ou será que, por trás dessa ignorância, se esconde um saber de outro tipo? Será que, na oposição entre conhecimento e ignorância, a ignorância é apenas ausência de conhecimento, ou é um tipo específico de conhecimento sobre a sexualidade e as diferenças de gênero? (ALÓS, 2011, p. 422, 423) 


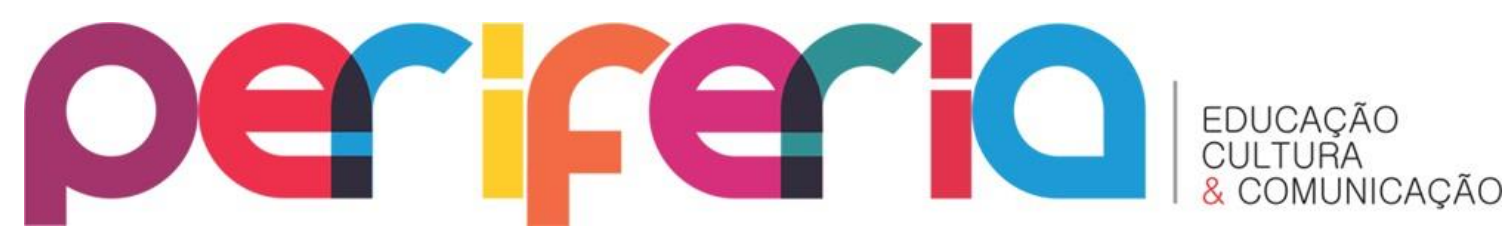

ISSN:1984-9540

DOI: $10.12957 /$ periferia.2019.36363

Nardi e Quartiero (2012), ao falar da experiência do curso Educando para a Diversidade, também discutem sobre a alegação do "não saber", levantada por profissionais como justificativa por não tratar dessas temáticas:

Este "não saber" protege, pois produz um distanciamento seguro, ou seja, o indivíduo, ao alegar o "desconhecimento" da questão, se desculpa de sua responsabilidade ética, pois como não sabia, não podia intervir. Este tipo de posicionamento, chamado por alguns de homofobia passiva, impede que se formulem questionamentos, uma vez que esses assuntos não entram na "ordem do dia". (NARDI, QUARTIERO, 2012, p. 72)

Ou seja, o suposto silêncio sobre sexualidade e questões de gênero na escola, esconde o fato de que a escola trata dessas temáticas o tempo todo. Esse profissional que alega não saber abordar gênero em sala de aula vivencia experiências em suas relações com estudantes e demais profissionais que estão envoltas em olhares sobre os papéis de gênero e as diversas normas que devem orientar a sexualidade. Por exemplo, é prática comum nas escolas, especialmente em turmas do primeiro segmento do ensino fundamental, a divisão de crianças por gênero em filas. Essa divisão carrega determinada concepção de gênero. 0 uso dos banheiros separados por gênero, não é prática exclusiva da escola, mas talvez seja um dos primeiros lugares em que a criança precisa se habituar a usar um banheiro específico, já que nas residências não existem banheiros divididos por gênero. Ou seja, existem determinados saberes relacionados a gênero e sexualidade que orientam a organização escolar. Mesmo alegando não saber tratar dessas questões, qualquer profissional da escola está envolto e (re) produz práticas baseadas em determinadas concepções de gênero e sexualidade.

Maria, ainda sobre o mesmo assunto, complementa que "existe um grande acordo entre pais, professores e gestão escolar que esse assunto não seja tratado para não fomentar, porque ninguém sabe muito bem do que tá falando, e não se deve falar sobre isso". Tatiana Lionço e Débora Diniz (2009), ao pesquisarem sobre a temática da diversidade sexual nos livros didáticos, apontam que: 


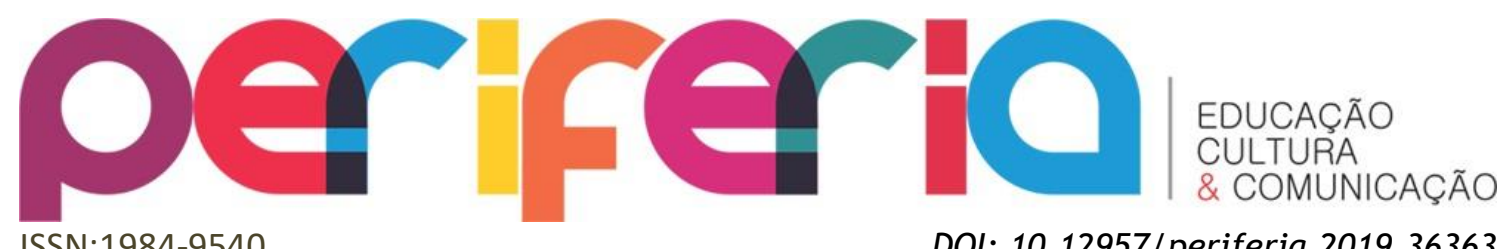

ISSN:1984-9540

DOI: $10.12957 /$ periferia.2019.36363

A heteronormatividade impõe um silêncio sobre essa temática: não há gays nas obras literárias, não há relações homossexuais nos textos de orientação sexual e, muito precocemente, as crianças aprendem a indexar o universo social pela dicotomia de gênero. Não existem corporificações para além desse binarismo, por isso não se fala de homossexuais, bissexuais, travestis ou transexuais. 0 silêncio é a estratégia discursiva dominante, tornando nebulosa a fronteira entre heteronormatividade e homofobia. (LIONÇO, DINIZ, 2009, p. 52)

Torna-se importante pensar no silêncio como reação a uma falta de preparo dos profissionais, como apontado pelas entrevistadas, mas também como causa e efeito da heteronormatividade. O que Lionço e Diniz chamam de "estratégia discursiva dominante". Porém, esse silêncio diz respeito principalmente a abordar essas temáticas de maneira formativa, em reuniões ou aulas, pois nos relatos das professoras elas nos trazem diversos exemplos de como a escola fala o tempo todo de gênero e de sexualidade, porém de maneira a reafirmar o que é visto como ridículo, jocoso ou anormal.

Essa realidade torna-se também entrave para que docentes encontrem pares para desenvolverem estratégias pedagógicas. Rita nos fala que nunca realizou um trabalho específico sobre essas questões, porém após participar do curso pensou em fazer. Ela conta que em uma reunião pedagógica falou com as/os colegas que desejava montar um projeto para discutir gênero, e mandou uma lista com várias sugestões de livros que havia encontrado em um site da internet. Ela diz que "algumas pessoas pareceram favoráveis, acharam importante, mas não foi para frente". Apesar disso, Rita acredita que a reação da escola não seria ruim caso houvesse um projeto sobre o assunto. Ela acha que não haveria resistência, ou interferência no sentido de não permitir que o projeto acontecesse. No entanto, informa que não realizou porque não obteve apoio e também teve dificuldades de encontrar material necessário, como os livros da lista que apresentou na reunião pedagógica.

Falando mais especificamente sobre as estratégias desenvolvidas pelas professoras, podemos destacar que grande parte das abordagens realizadas pelas professoras acontece nos momentos em que ocorrem conflitos em sala. A metodologia para lidar com esses conflitos é parecida nos relatos das quatro 


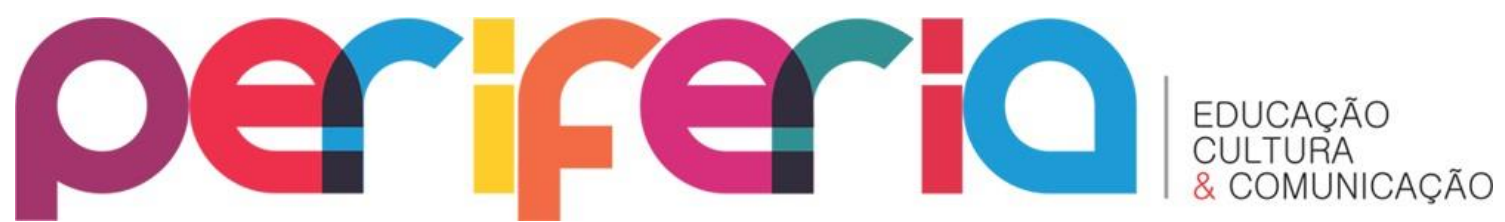

ISSN:1984-9540

DOI: $10.12957 /$ periferia.2019.36363

participantes. Rita, por exemplo, fala sobre casos em que adjetivos como "viado" ou "boiola" surgem na sala como forma de agressão verbal:

Eu primeiro pergunto: o que é viado? O que é jeito de boiola? Uma vez um menino falou que o outro tinha jeito de boiola. "Aquele jeito, tia. " "Aquele jeito como?" Aí a criança tenta dizer. "Jeito de menina". Aí a gente conversa com eles, não lembro se pede desculpa, mas para naquele momento, e volta e meia acontece de novo. É recorrente, entendeu? (Rita, 10/11/2016, NC)

Rebeca também traz um relato sobre como lidou com uma aluna que criava conflitos por conta da religião:

Uma aluna no início do ano brigava muito. Do nada começava uma discussão, porque alguém dizia que as pessoas iriam pro inferno. $E$ ela ficava muito exaltada, com muita raiva. Eu pensava: meu Deus, essa garota adulta vai ser um horror. Com 7 anos, ela ficava inflamada mesmo. Aí eu sempre falava: a outra pessoa tem o direito de pensar do jeito dela. Naquela hora resolvia, mas na semana seguinte ela voltava a provocar discussões. (Rebeca, 28/11/2016, NC)

Ao ser perguntada se a conversa foi a única estratégia, Rebeca respondeu: “Pois é, poderia ter elaborado alguma prática, mas não consegui".

É importante encontrar formas de lidar com as situações de violência e/ou conflito que surgem durante os momentos escolares. Rita, durante a conversa coletiva, por exemplo, mesmo não relatando nenhuma prática contínua ou algum projeto desenvolvido, fala sobre a importância de saber intervir nessas situações e também de suas dificuldades e, inclusive, de contribuições advindas do curso GDE. Ela percebe uma mudança de postura, quando diz que não sabe se dá conta de discutir os temas, mas não "deixa passar batido". Ela diz: "antes eu fingia que não escutava, entendeu? Ignorava. Porque não sabia o que fazer". A mesma professora, na conversa individual, disse que a melhor forma de lidar com os conflitos em sala seria "não fingir que não escutou ou que não viu".

Acho que tem que aproveitar essa oportunidade para trabalhar com a turma, pra problematizar entre eles, e discutir sobre aquilo, se foi 


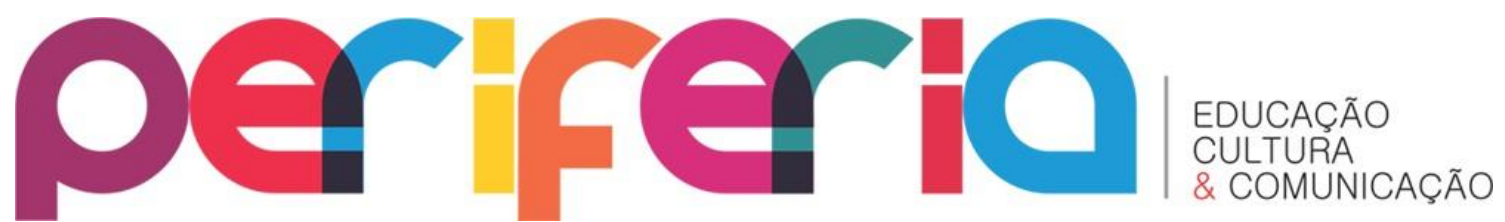

ISSN:1984-9540

DOI: $10.12957 /$ periferia.2019.36363

correto ou não, se eles já viram situações parecidas ou não, e a gente aproveitar. Quando surge assim do nada. Agora quando é intencional, a gente leva, "ah, eu quero falar sobre isso", aí é diferente. A gente pode levar uma música, pode ser uma história, um vídeo, então depende. Depende de como você quer, mas tem maneiras diferentes. Mas eu acho que esses momentos que surgem do nada, entre eles, são muito ricos. Porque não é nada planejado, intencional, e podem sair coisas muito boas dessas surpresas, dessas situações espontâneas. (Rita, 10/11/2016, NC)

Em outras experiências, essas temáticas causaram algum impacto nas práticas cotidianas e no currículo escolar. Maria traz um importante exemplo para pensarmos de que maneira podemos pensar as relações de gênero e sexualidade como temáticas que devem transpassar nossa prática cotidiana:

Por exemplo, essa semana eu estou falando de casa, então para falar de casa eu tenho que falar de quem mora na casa. Então, eu me aproveito desses momentos para falar para eles que existem casas em que moram dois homens com crianças, duas mulheres. Apresento para eles um material diversificado. Eu não faço um tema sobre isso, entendeu? É transversal. (Maria, 06/12/2016, NC)

Essa experiência traz um exemplo de como essas temáticas podem colocar o currículo em questionamento. Uma temática corriqueira na educação infantil passa a assumir outro caráter a partir do momento em que a professora questiona os saberes instituídos que se relacionam com o que se entende como família.

As experiências, relatos e reflexões colocadas pelas professoras nos fazem pensar junto com Louro (2004) como "estranhar o currículo" (p. 57). A partir das provocações da teoria queer, a autora coloca o currículo em ação em questionamento, dizendo que "quando pretendemos "estranhar o currículo" (...) seria um movimento de desconfiar do currículo (tal como ele se apresenta), tratá-lo de modo não usual; seria um movimento para desconcertar ou transtornar o currículo". (p. 67)

Araújo (2014) fala sobre a importância do exercício de colocar o currículo sob olhar desconfiado: 


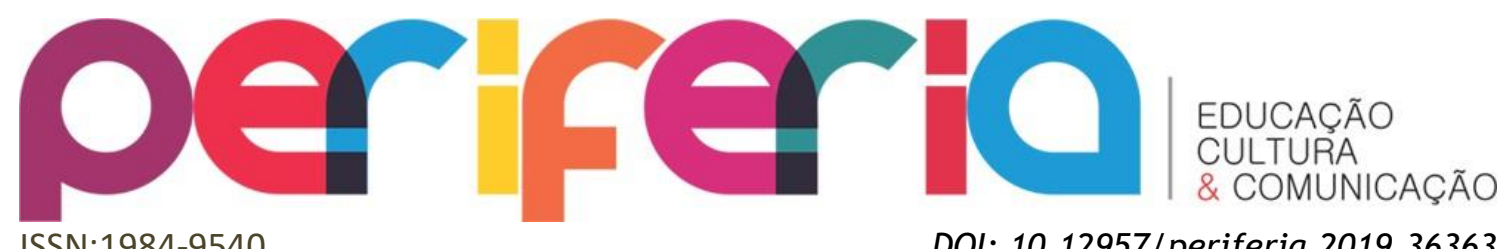

ISSN:1984-9540

DOI: $10.12957 /$ periferia.2019.36363

Discutir as conformações indicadas nas orientações curriculares e em que medida estas apontam para a desconstrução das naturalizações acerca da sexualidade e das relações de gênero é fundamental para desvelarmos ocultamentos, silenciamentos e apagamentos. (ARAÚJO, 2014, p. 4)

A partir dessas reflexões, e dialogando com os relatos das professoras, podemos pensar nas estratégias que elas vêm desenvolvendo para evidenciar essas questões nas situações cotidianas.

Uma das estratégias mais relatadas é aquela de levantar questionamentos a partir das certezas trazidas pelas/os estudantes. Nas intervenções das professoras, a metodologia encontrada é de produzir perguntas que desestabilizem as noções de normalidade envoltas nas visões de mundo das crianças. Essa tática é uma característica que as professoras desenvolvem para além das intervenções em momentos de conflito, mas também nas relações com responsáveis e colegas docentes. Também vai para além dos momentos de briga e discussão nas aulas, e começa a se infiltrar na prática cotidiana. Devido ao caráter complexo e amplo que essa estratégia passa a ocupar na prática pedagógica dessas professoras, podemos caracterizá-la como uma pedagogia do questionamento, que abarca mais do que a metodologia desenvolvida em aulas, mas passa a se configurar como uma forma de compreender os objetivos de se trabalhar com as noções de diferença e diversidade.

Meyer (2013) fala sobre essa postura onde se mudam algumas perspectivas no olhar da pessoa que educa. Segundo ela:

Caberia a nós, educadoras e educadores, investir em projetos educativos que possibilitem mudar os focos usuais dos processos de ensino-aprendizagem vigentes: da busca por respostas prontas para o desenvolvimento da capacidade de elaborar perguntas; das certezas para a dúvida e para a provisoriedade; do caráter prescritivo do conhecimento pedagogizado para um enfoque que estimule a desnaturalização de coisas que aprendemos a tomar como dadas. (MEYER, 2013, p. 13)

Dessa forma, o exercício do questionamento como fundamento para a produção de práticas e metodologias representa uma importante estratégia desenvolvida pelas 


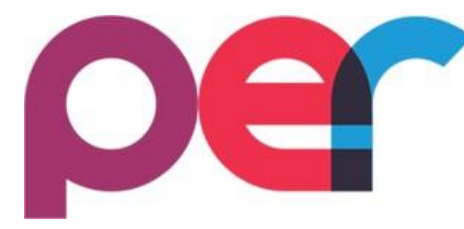

ISSN:1984-9540
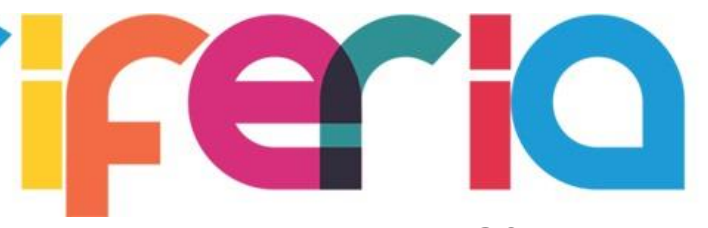

EDUCAÇÃO

CULTURA

\& COMUNICAÇÃO

DOI: $10.12957 /$ periferia.2019.36363

professoras, e nos oferece caminhos para pensar em práticas pedagógicas que busquem a desnaturalização das práticas de opressão na escola.

\section{Considerações finais}

Os relatos das professoras suscitam uma série de reflexões fundamentais para pensarmos na produção de práticas pedagógicas que estejam compromissadas com o enfrentamento das violências de gênero e sexualidade nas escolas. Longe de apontar caminhos, cartilhas ou modos de fazer, essas reflexões nos convidam a desestabilizar as estruturas que são base e justificativa para que essas violências existam. Ao utilizar do questionamento como fundamento de suas práticas, as professoras buscam colocar em xeque não apenas as ofensas e agressões, mas todo o arcabouço discursivo que produz elementos para que os sujeitos tornem-se agressores e agredidos. Assim, podemos pensar no questionamento como uma forma de produzir nossas práticas em nossas realidades, a partir das relações com os diversos sujeitos que compõem a escola, mas principalmente como forma de des-construir práticas, num processo de reflexão crítica contínua de nossas estratégias.

As nossas experiências também são extremamente importantes, e resgatar memórias de nosso tempo de estudante e também posturas e práticas atuais é uma metodologia muito interessante para se pensar os conceitos como gênero, sexualidade, raça e classe. Esses conceitos só fazem sentido quando podem ser exemplificados a partir das vivências dos sujeitos. Não tenhamos medo, inclusive, de reconhecer nas nossas práticas pedagógicas situações de violência, promovidas com nossa conivência ou mesmo através de nossa ação direta. Nossa experiência foi/é construída com base em normativas, e reproduzi-las é o caminho mais lógico. Em uma sociedade racista, não ser racista é um exercício. Em uma sociedade homofóbica, não ser homofóbico/a é um esforço. Ou seja, as opressões raciais, de gênero e sexualidade nos atravessam, e estamos todas/os em uma teia que hora nos coloca na posição oprimida, hora na de opressão, e em muitos casos nas duas ao mesmo tempo. 


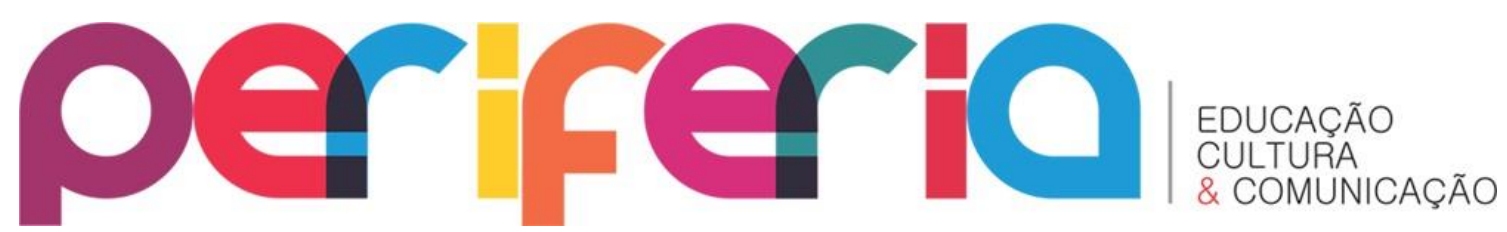

ISSN:1984-9540

DOI: $10.12957 /$ periferia.2019.36363

\section{Referências}

ALÓS, Anselmo Peres. Gênero, epistemologia e performatividade: estratégias pedagógicas de subversão. Estudos feministas (Florianópolis - UFSC), v. 19, n. 2, p. 421-449, 2011.

ARAÚJO, Ivanildo Amaro de . Diversidade sexual, diferença e currículo: por uma pedagogia decolonial nas periferias urbanas. In: III Seminário Internacional de Educação, Diversidade Sexual e Direitos Humanos, 2014, Vitória - ES. Anais do III Seminário de Educação, Diversidade Sexual e Direitos Humanos, 2014. v. 1. p. 1-17.

CAETANO, Márcio. Movimentos curriculares e a construção da heteronormatividade. In: RODRIGUES, Alexsandro; BARRETO, Maria Aparecida Santos Corrêa (org.). Currículos, gêneros e sexualidades: experiências misturadas e compartilhadas. Vitória, ES : Edufes, 2013, p. 63-82.

COLLING, Leandro; NOGUEIRA, Gilmar. Relacionados mas diferentes: sobre os conceitos de homofobia, heterossexualidade compulsória e heteronormatividade. In: RODRIGUES, Alexsandro; DALLAPICULA, Catarina; FERREIRA, Sérgio Rodrigo Silva. (Org.). Transposições: lugares e fronteiras em sexualidade e educação. $1^{\text {a}}$ ed.Vitória: EDUFES, 2014, v. , p. 171-183.

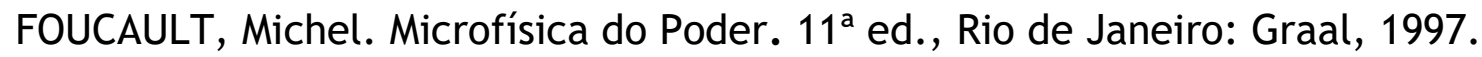

JUNQUEIRA, Rogério Diniz. Homofobia: limites e possibilidades de um conceito em meio a disputas. Bagoas, volume 1(1), jul/dez 2007, p. 145 a 166.

JUNQUEIRA, Rogério Diniz. Curriculo, cotidiano escolar e heteronormatividade em relatos de professoras da rede pública. In: Fazendo Gênero: diásporas, diversidades, deslocamentos, 9, Santa Catarina. Anais... Santa Catarina: Universidade Federal de Santa Catarina. 2010.

LIONÇO, Tatiana. DINIZ, Debora. Homofobia, silêncio e naturalização: por uma narrativa da diversidade sexual. In: LIONÇO, T. DINIZ, D. (orgs.) Homofobia e educação um desafio ao silêncio. Brasília: Editora UNB, 2009.

LOURO, Guacira Lopes (Org.). O corpo educado. Belo Horizonte: Autêntica, 1999.

LOURO, Guacira Lopes. Pedagogias da sexualidade. In: (org.) 0 corpo educado: pedagogias da sexualidade. Belo Horizonte: Autêntica, 2000.

LOURO, Guacira Lopes. Um corpo estranho: Ensaios sobre sexualidade e teoria queer. Belo Horizonte: Autêntica, 2004.

LOURO, Guacira Lopes. Gênero, sexualidade e educação: uma perspectiva pósestruturalista. Rio de Janeiro: Editora Vozes, 2012. 


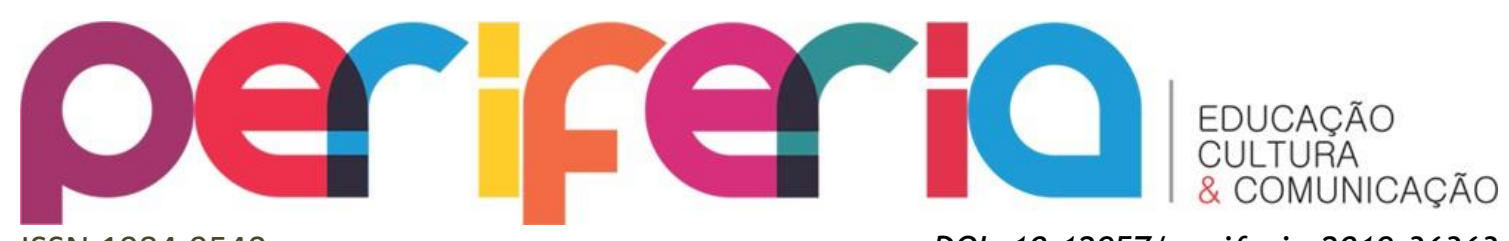

ISSN:1984-9540

DOI: $10.12957 /$ periferia.2019.36363

MEYER, Dagmar Elisabeth Estermann. Gênero e educação: teoria e política. In: LOURO, Guacira Lopes; NECKEL, Jane; GOELLNER, Silvana Vilondre. (Org.). Corpo, gênero e sexualidade: um debate contemporâneo na educação. 9. ed. Petrópolis: Vozes, 2013.

NARDI, Henrique Caetano; QUATIERO, Eliana. Educando para a diversidade: desafiando a moral sexual e construindo estratégias de combate à discriminação no cotidiano escolar. Sexualidade, Salud y Sociedad, n. 11, Rio de Janeiro, 2012.

$\mathrm{RICH}$, Adrienne. Heterossexualidade compulsória e existência lésbica.

RevistaBagoas, Natal, v. 4 n. 5, pag. 17-44, 2010. Disponível em:. Acesso em: 27 jul. 2014

SCOTT, Joan. Gênero, uma categoria útil de análise histórica. In: Educação e Realidade, 16(2). Porto Alegre, Faced, UFRGS, 1989.

SILVA, Tomaz Tadeu da. A produção social da identidade e da diferença. In: SILVA, Tomaz Tadeu da. Identidade e Diferença: a perspectiva dos Estudos Culturais. Petrópolis: Editora Vozes, 2005.

VIEIRA SILVA, Daniel. PAVELTCHUK, Fernanda de Oliveira. Olhares atentos: sobre a escola e a heteronormatividade. In: BICALHO, Pedro Paulo G. de. Gênero e Diversidade na Escola: práticas transversais, polifônicas, compartilhadas, inquietas. RJ: UFRJ, 2014. 